\title{
O professor-liderança Huni Kuin do Breu e os seus contextos de atuação: uma etnografia das relaçóes
}

\author{
MARIA ZENAIDE GOMES DE CASTRO \\ SECRETARIA DE ESTADO DE EDUCAÇÃO DO DISTRITO FEDERAL (SEEDF), BRASÍLIA (DF), BRASIL \\ HTTPS://ORCID.ORG/0000-0002-7043-326I
}

Huni Kuin é a autodenominação, que significa "homens verdadeiros" ou "gente com costumes conhecidos", do coletivo indígena também conhecido pelo etnônimo Kaxinawá. Falam a língua hantxa kuin (língua verdadeira), que faz parte da família linguística pano. Habitam uma extensa faixa territorial entre o Brasil e o Peru, distribuindo-se, no lado brasileiro, em áreas dos rios Tarauacá, Breu, Humaitá, Jordão, Murú, Envira e Purus. Segundo informações mais recentes disponibilizadas pelo Instituto Socioambiental (ISA), os Huni Kuin são uma população de 10.818 pessoas no Brasil e 2.419 no Peru ${ }^{1}$.

A etnografia descrita neste artigo iniciou-se no XI Curso de Formação para Professores do Magistério Indígena, realizado nos meses de agosto e setembro de 2014 no município de Plácido de Castro (AC), oportunidade em que atuei como mediadora de atividades a serviço da Secretaria de Educação do Estado do Acre ${ }^{2}$. Essa experiência inicial foi desenrolada em um projeto de mestrado, cuja pesquisa de campo realizou-se durante dois meses, entre novembro de 2014 e janeiro de 2015, na Terra Indígena Huni Kuin/Ashaninka do Rio Breu (doravante, TI Breu) ${ }^{3}$ e em Rio Branco.

\footnotetext{
1 Os números disponibilizados pelo ISA são oriundos da Secretaria Especial de Saúde Indígena (SESAI) e podem ser conferidos, assim como outros dados socioculturais sobre os Huni Kuin, através do link: Huni Kuin (Kaxinawá) - Povos Indígenas no Brasil (socioambiental.org) (acesso em: 03-12-2020).

2 Participaram do curso de formação 305 professores(as) de 12 etnias. Ao todo foram nove turmas, divididas pelos níveis de escolaridade e por etnias. Três dessas turmas eram exclusivamente Huni Kuin e foi com uma destas que atuei, formada por 52 professores e 2 professoras com Ensino Médio incompleto.

3 A Terra Indígena Huni Kuin/Ashaninka do Rio Breu encontra-se entre os municípios acreanos de Jordão (59,69\%) e Marechal Thaumaturgo (40,49\%). Os dados do censo de 2010 registraram uma população de 503 pessoas nessa área. A pesquisa de campo foi desenvolvida em estadias nas aldeias Jacobina e Vida Nova, ambas situadas nas barrancas do lado brasileiro do Rio Breu, cuja margem esquerda constitui território peruano. A população em cada uma dessas aldeias não passava de 50 pessoas à época. Sua localização geográfica e outros dados dessa Terra Indígena podem ser conferidos através do link Terra Indígena Kaxinawa/Ashaninka do Rio Breu | Terras Indígenas no Brasil (terrasindigenas.org.br), (acesso em: 03-12-2020).
} 
A escolha da TI Breu foi estratégica, visto que não há muitas produções etnográficas sobre essa região, em especial na área da educação. A opção pelas aldeias Vida Nova e Jacobina deveu-se à importância histórica de ambas na Terra Indígena e também porque suas principais lideranças nelas residiam à época. De saída, explico que, embora cada aldeia tenha suas lideranças, também chamados de "caciques" (xanembu), existem líderes que têm proeminência nas suas terras indígenas, sendo descritos como "lideranças centrais".

A primeira questão que me chamou atenção durante o curso de formação foi a constante menção sobre outras "funções/cargos" acumulados por alguns professores indígenas. Cerca de 10 professores também eram pajés ou estavam se preparando para tanto. Além disso, na turma com a qual trabalhei, vários docentes possuíam alguma relação de parentesco (filhos ou genros, na maioria dos casos) com pessoas tidas como lideranças locais ou mesmo centrais das Terras Indígenas. A princípio, ser pajé ou ter alguma relação próxima de parentesco com lideranças são características importantes na escolha de alguém como professor na comunidade. Essa relação não é peculiar ao caso que acompanhei, pois, como atesta Ingrid Weber (2004:71),

[v]ários trabalhos que, direta ou indiretamente, abordaram a temática da 'escola indígena’ [...], já chamaram a atenção para o estreito vínculo entre 'liderança' e 'professor'. Na maioria das vezes, eles estão ligados por fortes laços de parentesco.

A formação no curso foi de grande valia para essa turma de professores, visto que adotam o papel de mediadores entre o mundo Huni Kuin e o dos nawát. Os docentes possuem, na maioria dos casos, o reconhecimento da comunidade, principalmente pela aptidão na relação com o Estado e, ao alcançar essa competência de transitar entre os dois mundos, conseguem inspirar na escola suas concepções de conhecimento.

Em um certo sentido, talvez possamos dizer que o professor opera como um tipo de xamã, já que este é o sujeito capaz de se comunicar com seres de outras naturezas, agindo como um tradutor. Em termos analíticos, o "branco" pode ser visto como a encarnação de uma alteridade prototípica, evidenciada por sua caracterização como simplesmente nawá: o outro. O professor tem a capacidade de se comunicar com esse nawá, mas, por outro lado, essa ação não pode ser simples e deve se mostrar ampla, no sentido de que precisa estabelecer um conhecimento mútuo entre os dois.

A respeito das práticas dos xamãs na Amazônia, Manuela Carneiro da Cunha (1999:227) aponta que

[c]abe-lhes, sem dúvida, interpretar o inusitado, conferir ao inédito um lugar inteligível, uma inserção na ordem das coisas. Essa ordenação não se faz sem contestação e frequentemente é objeto de ásperas disputas que se assentam tanto na política interna como nos sistemas de interpretação.

4 No cenário do curso, o termo nawá fazia referência, segundo os professores indígenas, ao homem branco. No entanto, tal terminologia possui outras conotações a depender dos seus contextos, o que inclui outras etnias indígenas pertencentes à família Pano. Mas sempre se remete ao estrangeiro, o de fora. 
Tomado por essa perspectiva, o professor indígena opera então como um tradutor de mundos, que, no entanto, possui uma linguagem única, um olhar parcial, uma certa tentativa de reconstrução de sentido, de constituir relações (Carneiro da Cunha, 1999:229). Assim, o papel do docente como liderança, agente e executor do conhecimento se impôs como uma questão fundamental no meu primeiro contato com os Huni Kuin.

Nessa experiência, a categoria professor-liderança foi enunciada constantemente e questionamentos a respeito desse sujeito como mediador essencial entre a escola, a aldeia e as instituições estatais representantes da educação foram colocadas. A perspectiva de liderança explicitada por esses docentes se dá através da interação destes com os agentes não indígenas, como funcionários das Secretarias de Educação do Estado e do Município, bem como com a própria comunidade.

Logo, o objetivo desse artigo é analisar os contextos em que os professores indígenas Huni Kuin estão inseridos e, principalmente, as relações que constituem nesse universo, como aquelas com as ONGs (Organizações Não Governamentais), as Secretarias de Educação (Municipal e Estadual) e com suas respectivas comunidades. Esse enfoque permitirá analisar as propostas e as ações da educação escolar indígena Huni Kuin. Pretende-se, ainda, problematizar as relações das diversas instituições envolvidas no Estado do Acre com as comunidades foco da pesquisa, entendidas como um produto histórico resultante de um campo de tensões, produzido por interesses, percepções e demandas de diferentes atores sociais, políticos e econômicos.

Orientada por uma perspectiva etnográfica, a pesquisa se propõe a expor a complexa rede de interações que constitui a experiência escolar nas comunidades, mostrando como se estrutura o processo de produção de conhecimento e a correlação entre as esferas cultural, institucional e instrucional da ação pedagógica, objetivada principalmente na figura do professor. Logo, não houve o objetivo de produzir uma etnografia dos Huni Kuin em sentido estrito, mas sim de fornecer uma "descrição densa" (Geertz, 2008:04) da experiência de duas aldeias com a educação escolar.

\section{O professor e a liderança: professor-liderança?}

Antes era meu shubuã [termo nativo para aldeia], depois veio comunidade, aldeia, então tudo foi transformado. Foram criadas várias categorias de liderança dentro da comunidade. Por exemplo, como um governador: o cacique ainda faz essa comparação com a cidade. Tem mais, tem TI que tem o cacique geral, Santa Rosa do Purus, o Breu, cada aldeia tem seu cacique, como se fosse o prefeito. Ainda tem outras categorias de liderança que é como se fosse o secretário, por exemplo, o professor, ele é considerado o assessor do cacique, assessor da comunidade, pra assessorar porque aquele ator sabe ler, sabe escrever, sabe fazer os documentos, lê os documentos. $O$ segundo é o agente de saúde, depois a parteira tradicional. O AISAN, agente indígena de saneamento, o agente agroflorestal, o presidente da associação, a representação feminina (das mulheres) na aldeia, o representante da juventude, o representante da cultura, o capataz, que é herança do seringal, é o cara que coordena o trabalho do roçado, limpeza, coordena os trabalhadores. E tem aldeia que tem a polícia indígena, como é o caso do Caucho. Foi aprovado na Câmara de Vereadores, ganha salário e tudo. Não pode andar armado. No Breu é segurança. Hoje nas comunidades 
existem esses atores que são considerados as lideranças, mas o pajé não estava entrando muito nessa categoria, porque o trabalho dele é mais espiritual, os outros são atores políticos. Isso foi criado pelo Estado e aí a comunidade acata isso como uma maneira de arrecadar fundos. E ainda tem a figura da liderança tradicional, o ancião da aldeia, que lutou pela demarcação, etc. Hoje não existe mais respeito com os caciques, porque todo mundo quer ser liderança. Todos querem ter sua autoridade independente, então por isso o cacique fica sem função. A função dele é organizar, porque o que acontece é que todo mundo acha que é autônomo e isso acaba fragilizando a comunidade. Porque o que era um só, se desmembrou em vários. O problema maior é o presidente da associação, porque como ele arrecada os fundos, ele quer ser o xanenbu $u^{5}$ da aldeia indígena, o patrão. A figura da verdadeira liderança mesmo, no caso do nibu, ele fica fraco. Porque ele não tem espaço de atuação (Davi ${ }^{6}$, liderança indígena. Entrevista concedida dia 09 de janeiro de 2015. Grifos meus.

Davi é uma liderança atuante e reconhecida na luta pelos direitos dos Huni Kuin no Estado do Acre. A sua perspectiva sobre a construção das lideranças perante o Estado e, principalmente, nas comunidades, problematiza uma organização social resultante do contato estabelecido entre índios e nawás, o que possivelmente pode vir a justificar a adoção da terminologia liderança entre os índios do Estado do Acre.

No entanto, a liderança pressupõe uma série de direitos e deveres tanto com a relação estabelecida com o Estado, quanto com as comunidades, em que as diversas esferas sociais de atuação dentro e fora das aldeias estão divididas por habilidades e/ou categorias como: saúde, educação, captação de dinheiro, entre outras. Essa mesma divisão é apropriada e incorporada nos respectivos representantes na comunidade, como o agente de saúde, o agente agroflorestal, o professor, o presidente da associação etc.

Certamente essa profusão de líderes não ocorre sem maiores consequências. Tudo indica que a principal, comum em processos de segmentação, é aquela apontada por Davi em sua fala: o enfraquecimento da liderança que poderíamos chamar de tradicional, o xanembu. As causas apontadas são a atomização induzida pela expansão do universo relacional Huni Kuin e as demandas atualizadas na forma de recursos financeiros.

A educação/escola, que nos interessa nesse artigo, é personificada na figura do professor, que é a liderança desse quesito na comunidade e, também, no contato com as instituições e os agentes que regulam o sistema educacional na federação brasileira. Quem é essa figura? Em uma primeira aproximação, pode-se dizer que um professor precisa ser capaz de compreender a realidade indígena e formar estudantes de acordo com os conhecimentos ("tradicionais" e dos nawá) valorizados nas suas comunidades. A partir desse aspecto, percebe-se um vetor centrípeto, caracterizado pela autonomia do professor e autodeterminação comunitária.

Contudo, a educação indígena também segue uma grade curricular e um planejamento sequencial que, por mais que tenha sido construído observando-se os preceitos da interculturalidade, origina-se na matriz epistêmica não indígena. Esse vetor centrífugo gera desafios e instabilidades na atuação que são incorporadas na figura do professor. Tal ambiguidade, típica das posições liminares, talvez seja

5 Também grafado como xanen ibu, e, às vezes, contraído na fala como nibu, pode ser traduzido como liderança política.

6 Os nomes citados no artigo foram modificados a fim de preservar as identidades dos interlocutores. 
o aspecto que, do ponto de vista da sua atuação, coloque o professor em certa simetria com as noções de liderança de tipo tradicional. Que noções são essas?

Em primeiro lugar, é preciso explicar por que um líder, que em vários contextos culturais pode ser pensado como o centro do social, é, no caso indígena, uma figura liminar. Para tanto, recorro à análise de Pierre Clastres $(2003 ; 2004)$, que demonstra não haver uma correlação direta entre chefia e poder (pelo menos na sua forma coercitiva) entre os ameríndios.

Segundo o autor, quando surgem sinais da unificação dessas esferas, a qual poderia conduzir ao aparecimento da desigualdade - uma divisão entre senhores e súditos -, o procedimento adotado é geralmente a anulação desse chefe: sua destituição, seu abandono ou até mesmo sua morte. Na forma de um chefe sem poder reside sua instabilidade liminar. Mas, do ponto de vista de sua liderança formal, ele é quase sempre um líder "para fora", isto é, "quando circunstâncias e acontecimentos a colocam [sua sociedade] em relação com os outros" (Clastres, 2004:147).

Em segundo lugar, cabe entender quais seriam os atributos peculiares da chefia indígena. Segundo Clastres (2003:47), tais distintivos são recorrentes entre vários povos ameríndios e consistem basicamente em: 1) generosidade, de maneira que possa doar os seus bens para a sua respectiva comunidade; 2) dom da oratória, percebido na sua capacidade de falar perante a sua comunidade e com outras; 3) moderação, no intuito de sempre buscar a harmonia, a paz entre os seus. Com efeito, percebe-se que a chefia é fundamentalmente um entreposto de trocas ocupado por alguém com habilidade para circular bens, palavras e perspectivas.

Acredito que uma das situações observadas na pesquisa pode ser analisada através desse instrumental clastreano. Em um domingo, 30 de novembro de 2014, Carlos, Gustavo e Edivan, todos Huni Kuin, chegaram no município de Marechal Thaumaturgo (AC), onde se situa a TI do Breu. Estavam acompanhados de uma figura peculiar: um peruano, residente no Brasil e que também circulava muito na Europa. Inti, como ele se intitulava, dizia ser um xamã muito poderoso, conhecedor das práticas rituais e curativas dos Huni Kuin. Além disso, afirmava-se índio do povo Quéchua da região do Peru, mas que, pelo desgaste da convivência, tivera que se retirar.

Inti veio para a região com um propósito: realizar uma oficina entre jovens pajés, com uso intensivo de kampô, nixipae e rapé7. A intenção principal residia em documentar essas oficinas e fazer um filme para ser comercializado na Europa. Os produtores do filme em questão eram ingleses e iam para Marechal de batelão (uma espécie de barco). Diogo, professor Huni Kuin da T.I. do Breu, então ficara em uma situação um tanto quanto incômoda: Inti havia se hospedado na casa da sua mãe e aparentemente não estava agradando. Diogo relatou que o convidado ocupou a sala, nem rede tinha, comia sem pedir licença e usava as coisas da casa sem permissão.

Com a chegada, dois dias depois, dos estrangeiros ou gringos, como os Huni Kuin chamavam os produtores do filme, uma situação aconteceu. Diogo organizou uma reunião com as outras lideranças

\footnotetext{
7 Kampô, conhecida como "vacina do Sapo", é muito utilizada e difundida pelo povo Katukina, também residente em território acriano. Nixipae refere-se ao cipó Banisteriopsis, adicionado a outras plantas, principalmente Psychotria viridis (Rubiaceae) e Diplopterys cabrerana (Malpighiaceae). Essa mistura, que altera a consciência, também conhecida como Ahyuasca, é utilizada tradicionalmente por vários povos indígenas amazônicos e nas religiões chamadas ahyauasqueiras. Rapé, por sua vez, é o tabaco em pó usado em inalação.
} 
para decidir se eles poderiam entrar na TI. Em um passado recente, Inti esteve ali presente e havia ensinado os aprendizes de pajelância, inclusive Diogo e Gustavo, a usar o kampô e fazer o nixipae mel. Este é uma espécie de chá com mel, mais grosso e mais potente.

No entanto, quando partiu, Inti levou consigo muitas doses de kampô e litros nixipae, deixando a promessa de que, quando retornasse, traria o dinheiro referente aos produtos. Os Huni Kuin, por sua vez, lhe exigiram o pagamento como condição para entrar na TI e, sobre o filme, conversariam com a comunidade adiante. $\mathrm{O}$ pagamento exigido era em torno de 5 mil reais e Inti ferozmente respondeu que jamais envolveria dinheiro como condição de realizar seu trabalho espiritual. Os Huni Kuin sem hesitar lhe disseram que, em suas comunidades, ele não entraria mais.

No caso relatado acima, Diogo exerceu seu poder de moderação, o que o qualifica em primeira instância como um bom articulador e "fazedor de paz" (Clastres, 2003:46) e, além disso, aliado à nova perspectiva de liderança imposta no contato interétnico, como um bom captador de verba. Em segunda instância, sua generosidade (duapa) é medida com os bens que pode ofertar para a comunidade. Diogo situava-se como o melhor caçador da aldeia, reconhecido com tal pelos outros membros.

Fato igualmente digno de nota me foi relatado pela coordenadora do núcleo indígena do município de Marechal Thaumaturgo, relativo à posição de professor-liderança: os Jaminawá-Arara do rio Bagé, outro coletivo indígena, após retornarem do curso de formação no ano de 2014, compartilharam com a comunidade os conhecimentos adquiridos, entre eles a perspectiva da categoria de professor-liderança, aparentemente, até então, desconhecida por eles. Os docentes voltaram ao seu território se intitulando como lideranças indígenas e a comunidade acatou ascender a categoria de professor para a de liderança efetiva. Em contrapartida, impuseram a condição de que o salário desse professor, a partir daquele momento, passava a ser propriedade da comunidade. Afinal, liderar pressupõe generosidade.

No quesito oratória, Diogo, devido à sua habilidade de fala, era sempre solicitado pela comunidade, principalmente no contato com os nawá, com frequência enviado a Rio Branco para oficinas e reuniões com o governo e os órgãos indigenistas. A sua aptidão como bom orador foi condição estabelecida pela comunidade no processo de seleção. Conforme seu relato:

A minha escolha eu tive que fazer um pequeno teatro pra poder a comunidade me avaliar e acreditar que eu podia tá ensinando. O teatro era pra eu ensinar como eu ia trabalhar junto com os alunos e não só com os alunos, também se eu fosse pra uma formação pra eu tá apresentando meu trabalho. Por exemplo, dizer meu nome, qual aldeia, qual região. Se eu dava de apresentar, se dava de eu ser professor. A comunidade toda estava presente, as mulheres, as crianças, as lideranças (Diogo. Entrevista concedida dia 10 de dezembro de 2014).

O ato de representar a sua capacidade de oratória demonstra, de certa maneira, uma das habilidades essenciais no exercício como liderança local, tanto na perspectiva do ambiente escolar, quanto na esfera do contato com a alteridade, nesse caso representado pelo nawá, de maneira que é primordial sempre marcar a sua origem. Clastres (2003:53) ainda aponta que há outra característica observada na literatura etnográfica sul-americana: “[...] quase todas essas sociedades, qualquer que seja o seu tipo de 
unidade sociopolítica e a sua dimensão demográfica, reconhecem a poligamia; mas quase todas também a reconhecem como privilégio mais frequentemente exclusivo do chefe”.

Uma das discussões que ocorreram no curso de formação diz respeito à possibilidade de o professor Huni Kuin ter mais de uma esposa e, de fato, segundo os docentes, eles podiam possuir cerca de sete esposas. Entretanto, uma das poucas professoras da sala levantou-se brava e logo disse que isso era uma conduta do passado, atualmente proibida, que não era “coisa de Deus”. Entre respostas e acusações, um dos docentes mais velhos da turma logo se apressou: "Moça, você pensa desse jeito? Você não é mais Huni Kuin. Não respeita a liderança do professor".

Desse confronto, podemos deduzir que há o reconhecimento do professor enquanto liderança, afinal, pode se casar com mais de uma esposa. Fato é que alguns docentes Huni Kuin retornaram para suas aldeias com uma segunda ou terceira esposa, escolhidas entre as poucas professoras participantes do curso. A partir dessas situações e da presença masculina massiva no espaço escolar, pode-se inferir que, do contexto que situa os homens enquanto agentes envolvidos de forma peculiar com o mundo da alteridade, as mulheres estão apartadas, pelo medo dos seus respectivos maridos no que tange ao envolvimento com outros homens ou pelo receio diante de outros maridos em potencial. Conforme o relato de Sebastião:

Nossa cultura é diferente, a de vocês é diferente. Sendo uma professora, mulher, tem que fazer o curso, daqui ela vai pra Rio Branco. Fica um mês, dois meses, o marido fica na aldeia. Ela não tá sabendo como tá o marido, nem o marido sabe dela lá. Não é muito certo. Porque eu já fui muito em reuniões e as pessoas se encontram, as pessoas se envolvem. Aí é bom homem, porque homem pode. Mulher não. Porque às vezes não faz coisa certa lá, a mulher, aí vai querer separar (Entrevista concedida dia 23 de dezembro de 2014).

No entanto, para além de todas as características da liderança indígena, é preciso levar em conta como é feito o escopo dessa chefia, ou seja, como é a fabricação de seu corpo nas sociedades ameríndias. Antonio Guerreiro Júnior (2011:110, grifo do autor) afirma que "ninguém nasce um chefe 'pronto', mas que é preciso ser feito chefe ao longo de toda a vida". Ainda segundo ele, "[a] fabricação dos chefes não trata apenas da fabricação de corpos individuais, mas de corpos coletivos" (ibid.:122).

Para tanto, cabe notar que a construção dessa liderança demanda alguns atributos necessários para a construção de seu corpo. Como, por exemplo, a 'hereditariedade', sinalizada por Guerreiro Júnior (2011:104):

[...] os chefes podem ser pensados como uma conexão entre o presente e um passado específico, pessoal, nomeado e localizado, do qual nem todos participam por igual. São as relações de continuidade entre os aneta $\tilde{o}^{8}$ do presente e do passado que permitem produzir, refinar e perpetuar identidades coletivas duráveis no decorrer do tempo.

8 Termo para 'chefe' na língua Kalapalo, povo ameríndio da região do Alto Xingu, localidade onde o citado antropólogo desenvolve suas pesquisas. 
No caso da região do Breu, podemos pensar na posição do professor Leonardo. Este é o filho primogênito de Sebastião, uma das lideranças mais importantes da TI e, como tal, preparado para ocupar também esse lugar. Leonardo é visto por todos como uma pessoa digna de confiança. Entretanto, como podemos verificar em McCallum (2015:136):

[...] nenhum corpo individual é inteiramente confiável, qualquer que seja sua história pessoal. Esta é uma consequência da instabilidade corporal do pensamento (xinan). A confiança como pensamento tem uma qualidade líquida. [...] [P] ara muitos povos amazônicos, a corrente sanguínea é o veículo ativo da consciência. É como os pensamentos fluem pelo corpo. [...] $[X]$ inan (os pensamentos) são transportados pelas veias e artérias do corpo em forma líquida, e de fato os sinais apontam para isto. Embora eu nunca tenha ouvido alguém dizer precisamente tal coisa, os Huni Kuin afirmaram que o pensamento permeia o corpo inteiro, como disseram a Kensinger nos anos 1950 e 1960.

Dessa perspectiva, Leonardo naquele momento era o mais digno de confiança da região, afinal havia assumido o posto de liderança da aldeia Jacobina recentemente. Também é filho de liderança forte, nas palavras de muitos Huni Kuin. Assim, podemos retomar o termo da ascendência proposta por Guerreiro Júnior (2011:104) e o atributo de possuidor de "bons pensamentos" como observado em McCallum (2015:136).

Sob essa luz, é possível analisar o caso de Francisco, chefe da T.I., presidente da Associação Huni Kuin do Breu (Akarib) e ex-professor da Escola Rainha da Floresta. Sua liderança estava em "corda bamba”, já que reside no Município de Cruzeiro do Sul (AC) e, como relatado pelos parentes Huni Kuin, quase não aparecia na Terra Indígena, o que dificultava o estreitamento das relações, no que tange à articulação de projetos e à própria comensalidade desse sujeito enquanto líder das necessidades particulares da comunidade, principalmente o fortalecimento da Akarib. Muitas reclamações referentes à panema $a^{9}$ de Francisco e a sua pouca articulação política fizeram com que seu papel de professor da região fosse revogado pelos parentes Huni Kuin. A comunidade não o defendeu perante a Secretaria Municipal de Educação (SME) quando houve a revogação de seu salário de professor.

Importante ressaltar que a questão da liderança para os Huni Kuin é uma qualidade transitória, como podemos ver em Lagrou (1991:07): “O líder Huni Kuin só existe enquanto tiver a confiança do grupo, e isto apesar das ou graças às críticas que recebe". Diferente, portanto, do observado por Guerreiro Júnior (2011:103) entre os Kalapalo. Assim, a liderança de Francisco estava estremecida e já não preenchia amplamente as qualidades essenciais de uma chefia clássica: a oratória, a moderação e a generosidade.

A partir desses exemplos, deduz-se que a construção da liderança a cargo da comunidade se cruza com o papel de professor construído na sociedade não indígena, o qual está restrito à ação pedagógica e administrativa no âmbito da escola, regulada pelo seu desempenho como docente, pela realização de relatórios, entre outros requisitos. No caso em tela, todavia, a comunidade atua como regulador do professor-liderança nas duas esferas: a indígena e a não indígena.

9 Termo usado entre os Huni Kuin para se referir à preguiça, vítima de feitiço, tristeza, apatia e a fraco desempenho. 
Contudo, podemos inferir ainda que a fabricação do corpo do professor-liderança é a mescla das duas sociedades, uma fabricação intercultural. A sociedade não indígena oferece a formação pedagógica e a informação política entre os dois polos, enquanto a coletividade Huni Kuin confere funcionalidade a esse conteúdo na organização social indígena, principalmente no que compete ao espaço da escola.

\title{
Em terra de cego quem tem olho é rei: o professor na visão das instituições burocráticas
}

\section{Ato 1: Secretaria de Educação do Estado do Acre (SEE) e Secretaria Municipal de Educação (SME) de Marechal Thaumaturgo}

\begin{abstract}
Essa questão do professor ser uma liderança foi criada a partir do momento que foram criadas as escolas, ou seja, foi com a CPI [Comissão Pró-Índio do Acre]. Antes, tinha escolas, mas não em favor das comunidades; o objetivo era amansá-los, foi uma estratégia de amansamento e quando a CPI começa a fazer um trabalho em 1983, no Jordão, em Tarauacá, começou a se criar essa coisa do professor-líder porque o acesso à educação, à escrita faz com que ele tenha um maior acesso à cidade, à nossa sociedade principalmente. $\mathrm{E}$ isso empodera ele dentro da comunidade. $\mathrm{O}$ diálogo fica mais próximo. E ele vinha pra cidade fazia curso... então... aquela coisa: em terra de cego quem tem olho é rei" (Aparecida, Coordenadora SEE/AC. Entrevista concedida em 22 de novembro de 2014).
\end{abstract}

Aparecida, que foi coordenadora da educação escolar indígena no Estado do Acre, utilizou-se de um ditado popular para explicar a posição do professor-liderança: "em terra de cego quem tem olho é rei". Fato é que a liderança do professor, segundo o depoimento, reverbera apenas dentro da comunidade, nunca perante o Estado, nesse caso representado pela Secretaria de Educação.

Afinal, que sujeito é esse que se forma para a docência? Há a percepção de que se revela impossível ao professor em uma aldeia ser apenas um docente a ensinar uma técnica disso ou daquilo, porque ele estabelece relações em outras escalas, articulando o plano local com diferentes agentes do governo. O professor é protagonista nessas relações. Confrontos de visões são estabelecidos desde sua origem, afinal, aparentemente a criação do docente como liderança é uma construção "de fora para dentro", no discurso veiculado pelas instituições. Uma construção produzida por não índios, segundo Aparecida, para conduzir um processo de escolarização alternativo dentro das comunidades ameríndias:

Então a SEE pegou esse processo em andamento, dialogou com a CPI. A CPI foi quem orientou o primeiro curso de formação, elaborou um currículo mínimo para que a SEE trabalhasse o primeiro curso, ajudou a localizar as escolas, porque a CPI não atendia a todos, era um número pequeno e a SEE ampliou isso. A gente já pegou essas ideias, essas construções todas e seguimos (Aparecida, Coordenadora SEE/AC. Entrevista concedida em 22 de novembro de 2014). 
Nesse contexto, desenha-se uma relação conflituosa, a partir dessa herança deixada pela CPI para a SEE. Como trabalhar com essa perspectiva de liderança se para o Estado o que interessa é o professor? Fato é que, como salientado por Davi, a reorganização do sistema social das comunidades foi permeada pelas construções da ordenação social da sociedade não indígena. Afinal, isso garante recursos a esses coletivos.

O papel de liderança do professor indígena, como dito, funciona como o elo na relação da aldeia com a sociedade não indígena. No entanto, representa um problema ao sistema burocrático, visto que o docente enquanto ator político e, de certo modo, como um sujeito que acessa determinados conhecimentos para a comunidade, posiciona-se como o mais adequado para articular diretamente com os atores não indígenas. Isso representa desafios e avanços tanto na perspectiva das comunidades e, principalmente, das instituições.

Mas como lidar com essas diferenças de perspectivas? O que está implicado nessas relações que torna esse sujeito pivô de conflitos ligados ao espaço escolar? São as percepções do que deve ser essa escola indígena, pois enquanto o governo atua com a marca de uma instituição de ensino diferenciada de modo verticalizado, os indígenas operam com a lógica da interculturalidade, que busca uma relação de troca horizontal.

Diferenças de perspectivas também acontecem no processo de escolha do professor indígena, visto que, enquanto as comunidades optam por determinados padrões de representatividade, que funcionam dentro daquela dinâmica social (a qual considera que a escola ultrapassa os limites da aldeia), a SEE busca outro conjunto de habilidades:

A gente concorda que seja pela comunidade, mas que se tenha critérios; muitas vezes, as comunidades não utilizam o critério da competência, o critério do conhecimento que o professor tem. Utilizam mais o parentesco, já melhorou bastante, à medida que as comunidades vão se conscientizando do papel da escola, vão buscando escolher o professor que se adeque a que querem. Mas, na maioria dos casos, os professores são escolhidos pelo critério do parentesco. Essa questão do parentesco é muito forte, quem escolhe o professor? É a liderança. A liderança muitas vezes usa o critério do parentesco. Muitas vezes na comunidade tem aquele indígena que estuda, se esforça, que tem facilidade na sala de aula, gosta, mas não é o escolhido, porque não está próximo, não é do clã. Nessas relações internas nós não interferimos, respeitamos. O nosso papel é dar formação. Não é concordância, é respeito (Aparecida, Coordenadora SEE/AC. Entrevista concedida em 22 de novembro de 2014).

Para Grupioni (2006:24), o professor indígena tem duas funções essenciais, pois ao passo que prepara discentes para conhecerem seus direitos dentro da sociedade envolvente, necessita assegurar que estes prossigam no exercício de sua cidadania dentro da comunidade: "[O]s professores indígenas, em seu processo de formação, têm que, o tempo todo, refletir criticamente sobre as possíveis contradições embutidas nesse duplo objetivo, de modo a encontrar soluções para os conflitos e tensões daí resultantes". 
É da competência do professor indígena também fazer o calendário escolar e elaborar o projeto político pedagógico de sua escola. Mas, para respeitar o Referencial Curricular, faz-se necessário constituir os objetivos educacionais, adaptar a grade curricular, selecionar o conteúdo das disciplinas, bem como elaborar um sistema de avaliação. Tais procedimentos também são parte das responsabilidades dos docentes indígenas. Essa não é uma empreitada simples: os órgãos oficiais de ensino dos Estados, em muitos casos, forçam os professores a cumprir os programas e não percebem que os princípios pedagógicos dos povos indígenas são baseados em outras lógicas de ensino-aprendizagem.

Exemplo dessa abordagem reside na adoção de determinados programas que são impostos como uma maneira de estabelecer metas no sistema nacional de educação. Dessa maneira, políticas públicas de alfabetização e letramento chegam de maneira engessada às comunidades indígenas e interferem diretamente na construção de currículos diferenciados, além de submeter o professor a determinadas burocracias.

Diogo relatou que alguns professores da Terra Indígena participam de um programa chamado Pacto Nacional pela Alfabetização na Idade Certa (PNAIC). Por sua vez, é preciso compreender que o PNAIC “[...] é um compromisso formal assumido pelos governos federal, do Distrito Federal, dos estados e municípios de assegurar que todas as crianças estejam alfabetizadas até os oito anos de idade, ao final do $3^{\circ}$ ano do ensino fundamental" ${ }^{\prime 10}$.

O Pacto possui quatro princípios centrais que guiam o trabalho pedagógico na alfabetização:

1. o Sistema de Escrita Alfabética é complexo e exige um ensino sistemático e problematizador; 2. o desenvolvimento das capacidades de leitura e de produção de textos ocorre durante todo o processo de escolarização, mas deve ser iniciado logo no início da Educação Básica, garantindo acesso precoce a gêneros discursivos de circulação social e a situações de interação em que as crianças se reconheçam como protagonistas de suas próprias histórias; 3. conhecimentos oriundos das diferentes áreas podem e devem ser apropriados pelas crianças, de modo que elas possam ouvir, falar, ler, escrever sobre temas diversos e agir na sociedade; 4. a ludicidade e o cuidado com as crianças são condições básicas nos processos de ensino e de aprendizagem.

O Pacto prioriza o ensino de português e matemática; compromete os entes governamentais a realizar avaliações anuais; garante o apoio entre os estados e municípios, assim como conta com quatro frentes de atuação: formação continuada dos professores alfabetizadores; materiais didáticos; avaliações sistemáticas (no caso relatórios mensais, como citado pelo professor Diogo); além de gestão, mobilização e controle social ${ }^{11}$.É importante notar que a cartilha utilizada, nesse contexto, volta-se à educação do campo e acaba corroborando a imposição de políticas públicas generalizantes para uma realidade sociocultural totalmente específica e diferenciada como a indígena.

Apenas os professores que lecionam no primeiro ciclo (do $1^{\circ}$ ao $3^{\circ}$ ano) podem participar. No entanto, a remuneração adicional do PNAIC, de $\mathrm{R} \$ 200,00$, só é paga algumas vezes, pois está condi-

10 Disponível em: http://pacto.mec.gov.br/o-pacto. Acesso: 20-04-2015.

11 No site referente ao PNAIC, não fica claro como seria a gestão, mobilização e, principalmente, o controle social do programa com relação à educação escolar indígena. 
cionada à entrega de uma ficha com o perfil da turma para a Secretaria Municipal de Educação (SME). A questão da ficha enumera uma série de fatores que dificultam o trabalho docente e também da SME. Um deles é que o relatório versa sobre a aquisição da cultura escrita e letrada da língua portuguesa, ao passo que em uma escola indígena, específica, diferenciada, bilíngue e intercultural, as aulas são ministradas na língua materna, ou seja, em hantxa kuin. Outro exemplo, segundo o professor Diogo, se encontra na entrega da ficha. É preciso ir até a cidade mensalmente para isso, de modo a receber a bolsa. Por questões geográficas e financeiras, a eficiência dessa política educacional fica comprometida, devido à ausência do acompanhamento pedagógico nas aldeias, bem como ao custeio do combustível para o transporte a cargo do professor.

No caso específico da região do Breu, o acesso à terra indígena equivale a dois dias de viagem pelo rio Juruá e pelo rio Breu na época do verão, o que equivale a 100 litros de gasolina, com preço médio de $\mathrm{R} \$ 6,00$ a $\mathrm{R} \$ 7,00 / \mathrm{L}$. Já na seca, leva-se em torno de seis a nove dias e, provavelmente, consomem-se mais litros de gasolina. Ou seja, o valor da bolsa não cobre os gastos do acesso a ela. Além disso, o professor, para tê-la, acaba assumindo tantas obrigações que dificultam não só o seu trabalho, mas também comprometem o tempo de vivenciar o próprio grupo em suas práticas diárias.

O PNAIC está presente no município desde 2013 e o ideal é que a formação continuada dos alfabetizadores ocorra quatro vezes ao ano. No entanto, em 2014 apenas uma formação aconteceu, devido à ausência de recursos ${ }^{12}$. A princípio, os docentes indígenas não seriam incluídos na implementação da política no município. Os funcionários da SME relataram dificuldades com esse grupo, principalmente pela "falta de manejo" da língua portuguesa. Porém, o interesse em aprender por parte dos professores mobilizou a SME, que optou por incluir as comunidades indígenas.

Entretanto, como se vê, apesar dos esforços e da legislação específica, a efetivação da escola no meio indígena ainda encontra dificuldades de ordem prática e de resistências das esferas pertinentes do Estado. Uma delas é a indagação dos órgãos públicos sobre a educação específica e diferenciada e, também, sobre a forma pela qual os docentes indígenas atuam nas escolas. Destarte, têm-se gestores públicos forçando políticas que contrastam com a realidade sociocultural dos povos indígenas e, nesse caso, sobressaem-se os impedimentos burocráticos do sistema de ensino não indígena. Como reforça Grupioni (2009:61): “Com o passar dos anos, vê-se alargar a distância entre o que está preconizado como proposta de uma educação diferenciada e os meios administrativos postos em prática para efetivá-1[a]”.

Há outros fatores a serem analisados em termos burocráticos que os professores indígenas nem sempre compreendem. Por exemplo, qual a diferença entre a regulação da educação escolar indígena em âmbitos municipal e estadual? Aparecida, quando questionada sobre isso foi categórica:

Na verdade, não tem diferença, porque nós temos escolas municipais em três municípios aqui no Acre. Na resolução $n^{\circ} 3$, está colocado que as escolas podem ser assumidas pelo município se tiver anuência da comunidade. A gente não tem nenhum documento até hoje que prove essa anuência. Mas esses três municípios resolveram assumir e no momento que assumiram as escolas multiplicaram, porque as comunidades começam a se dividir e formar novas aldeias, tem novos professores e

12 Ver mais em: https://www.facebook.com/pnaicmarechal.thaumaturgo?fref=ts. Acesso: 21-04-2015. 
isso faz com que se tenha mais renda. Em relação ao funcionamento da escola, em relação ao currículo, a escola indígena mesmo, como funciona, não tem nenhuma diferença. Os recursos são os mesmos, passam direto para o município ou para o Estado. Eu acredito que o que eles colocaram diferente é que as escolas municipais estão mais próximas das SME e às vezes facilita ou dificulta, e nós estamos mais distantes. $\mathrm{O}$ nosso contato é por meio do técnico que temos em cada município. A maioria desses técnicos são indígenas e eles fazem a ponte entre a gente e as escolas. Nós temos aqui as atividades de campo, que faz tempo que não fazemos. Temos a nossa presença direta, mas no geral a nossa presença é indireta. E não acontece como na rede municipal, em que eles conseguem resolver os problemas com o gestor. A contratação de professores parece mais fácil, os serviços que são oferecidos. Acho que é mais uma questão de relação de todos os recursos, orientações legais, tudo é a mesma coisa, não modifica. Marechal Thaumaturgo, Jordão e Santa Rosa do Purus são as localidades que possuem escolas indígenas na rede municipal. As escolas são do sistema municipal, mas quem dá formação é o Estado e quem faz o acompanhamento é o Estado. Nesses três municípios, a gente faz parcerias. O Estado assume a formação e o acompanhamento pedagógico (Aparecida, Coordenadora SEE/AC. Entrevista concedida em 22 de novembro de 2014).

Entretanto, quando vêm à tona problemas com relação à verticalização e ao descumprimento da legislação por parte dos municípios, Aparecida assume a fragilidade do sistema:

Esse conflito é antigo. Nós sempre perguntamos: vocês querem continuar na rede municipal? Porque tendo anuência da comunidade, vocês podem voltar pro Estado. É bastante complicado, nós não temos o controle de tudo. Mas a gente faz discussões, conversa com as equipes pedagógicas da SME, no entanto, existe uma resistência dos técnicos em aceitar um projeto diferente. A formação que eles têm e quando vão pra comunidade ocorrem os conflitos. Mas os nossos professores foram os responsáveis pela elaboração dos projetos, então, eles têm bastante conhecimento pra discutir com os técnicos da SME. Só que existe essa coisa da hierarquia, do poder. E aí não conseguem impor. A intervenção maior quem tem que fazer é a comunidade, não a gente, porque não estamos lá no dia a dia" (Aparecida, Coordenadora SEE/AC. Entrevista concedida em 22 de novembro de 2014).

É possível constatar que a educação indígena apresentou um crescimento significativo nos últimos anos, conforme podemos observar na tabela abaixo, o que não quer dizer que a qualidade tenha seguido nesse mesmo ritmo, assim como o capital destinado às escolas diferenciadas não registrou aumento significativo. O Estado somente investiu a mais como resposta às demandas dos povos indígenas. 
Tabela 1 - Número de estabelecimentos de Educação Escolar Indígena no Brasil, de 1999 a 2005

\begin{tabular}{|c|c|c|}
\hline Unidades da Federação & $\begin{array}{l}\text { Número de Escolas } \\
\text { Indígenas } 1999\end{array}$ & $\begin{array}{l}\text { Número de Escolas } \\
\text { Indígenas } 2005\end{array}$ \\
\hline Brasil & 1.392 & 2.323 \\
\hline Acre & 75 & 136 \\
\hline Alagoas & 10 & 13 \\
\hline Amapá & 38 & 57 \\
\hline Amazonas & 370 & 783 \\
\hline Bahia & 35 & 51 \\
\hline Ceará & 24 & 36 \\
\hline Espírito Santo & 10 & 7 \\
\hline Goiás & 2 & 2 \\
\hline Maranhão & 138 & 225 \\
\hline Mato Grosso & 145 & 176 \\
\hline Mato Grosso do Sul & 63 & 46 \\
\hline Minas Gerais & 5 & 10 \\
\hline Pará & 62 & 91 \\
\hline Paraíba & 29 & 28 \\
\hline Paraná & 24 & 28 \\
\hline Pernambuco & 46 & 119 \\
\hline Rio Grande do Sul & 40 & 49 \\
\hline Rio de Janeiro & 2 & 3 \\
\hline Rondônia & 48 & 69 \\
\hline Roraima & 135 & 257 \\
\hline Santa Catarina & 25 & 31 \\
\hline São Paulo & 7 & 29 \\
\hline Sergipe & 1 & 1 \\
\hline Tocantins & 58 & 76 \\
\hline
\end{tabular}

Fonte: http://portal.inep.gov.br/documents/186968/484154/Estat\%C3\%ADsticas+sobre+educa\%C3\%A7\%C3\%A3o+escolar+ind\%C3\%ADgena+no+Brasil/fcaed45e-c69f-4767-8b91-055e416aec48?version=1.1

De sua perspectiva como Secretária Municipal de Educação de Marechal Thaumaturgo, Fátima pondera sobre o seu trabalho com as populações indígenas da região:

Sabemos que eles atuam com educação diferenciada e nós respeitamos isso. Então, fazemos os acompanhamentos. Antes eu não sabia o trabalho de um supervisor, mas depois da caminhada 
participei de uma formação pra técnico indígena, em 2012, então comecei a entender qual o meu papel ao chegar nas aldeias. Avaliar tudo, não só o trabalho do professor, mas a participação da comunidade. No nosso caso aqui, todos dão aula, os pajés, os agentes de saúde, os agentes agroflorestais. É importante observar como eles estão se adaptando com essa escola. Eles alfabetizam as crianças na língua indígena. Eu observo pra ver se eles realmente estão usando a identidade deles (Entrevista concedida em 19 de dezembro de 2014).

Importante ressaltar que a SME, nesse caso específico, atua mais como um órgão fiscalizador que de fato como um ente que assessora e acompanha as escolas e os professores indígenas. Discurso semelhante me foi relatado pelo assessor pedagógico indígena da região, contratado tanto pelo Estado quanto pelo Município, quando o acompanhei no final do ano letivo de 2014 nas aldeias indígenas da TI do Breu. Sua preocupação era a coleta dos relatórios e boletins, como também a realização de novas matrículas - pois, segundo ele, quanto mais matrículas, mais verba para as escolas. Mostrou-se categórico ao afirmar que o seu trabalho consistia em fiscalizar a atuação dos professores no cumprimento da carga horária e dos processos administrativos cabíveis, haja vista que, com isso, conseguiam garantir verba para a merenda escolar, os materiais didáticos e os salários dos docentes.

Fátima, ao longo de nossa conversa, sempre se mostrou preocupada com os documentos, posto que, aparentemente, existe uma grande dificuldade de fazer com que os professores atuem na esfera administrativa, para além da docência. Segundo ela:

Antes, os documentos não importavam muito com relação às escolas indígenas, mas, com o tempo, descobrimos que não era o professor que preenchia o boletim, mas sim o aluno. No entanto, é necessário, porque quando eles saem da aldeia, quando termina o $5^{\circ}$ ano, precisam dar a continuidade do saber e, por precisar da transferência pra vir estudar aqui no município, foi quando começamos a implementar essa coisa do boletim, do relatório final, pois se precisa desses documentos aqui na cidade. Existe uma lei. Não tem como eles terem acesso à escola da cidade sem esses documentos (Entrevista concedida em 19 de dezembro de 2014).

Mais uma vez, nos deparamos com o confronto entre a diferença da educação escolar indígena e o sistema regular de ensino. A primeira é submetida aos mesmos padrões de avaliação e monitoramento do segundo. Talvez por esse motivo, muitos municípios optem por endurecer no que diz respeito a calendários específicos, disciplinas, materiais didáticos, entre outros. Mais um exemplo da falta de autonomia e de diferenciação concreta da escola indígena é a avaliação dos estudantes pela Provinha Brasil ${ }^{13}$, que não aprecia a especificidade de cada povo ameríndio e, dessa forma, não leva em consideração o direito à educação diferenciada.

13 A Prova Brasil e o Sistema Nacional de Avaliação da Educação Básica (Saeb) são avaliações para diagnóstico em larga escala, desenvolvidas pelo Instituto Nacional de Estudos e Pesquisas Educacionais Anísio Teixeira (Inep), vinculado ao Ministério da Educação (MEC). Têm o objetivo de avaliar a qualidade do ensino oferecido pelo sistema educacional brasileiro a partir de testes padronizados e questionários socioeconômicos. 


\section{Ato 2: Organização do Professores Indígenas do Acre (OPIAC)}

Naquela época, quando a CPI começou a atuar no Acre, foram feitas muitas viagens, começou um mapeamento das Terras Indígenas e com isso não tinha nenhum professor. A CPI trouxe 28 professores indígenas pra ensinar operações matemáticas, não era nem ler e escrever, mas aprender matemática. E, naquela época, esse professor que veio tinha essa função de pesquisar, de liderar, pesquisar sobre as línguas, os conhecimentos, coordenar o povo pra reivindicar os direitos. Naquela época, tinha essa necessidade. A educação é a base. Com o tempo, fomos pra 40 e hoje temos 590 professores, destes 120 são graduados no Ensino Superior (Marli, coordenadora da OPIAC. Entrevista concedida em 26 de novembro de 2014).

Marli é professora indígena e, como tal, situa o contexto histórico da categoria de docente enquanto liderança, em meio às lutas dos povos ameríndios pelo direito à terra, educação e saúde. Reafirma a atual posição desse professor dentro da comunidade, com o papel essencial de assegurar as condições dessa educação, em confronto com o estabelecido pelos órgãos burocráticos no cotidiano. Analisa, ademais, as quatro atribuições da docência na esfera da sociedade envolvente:

Estamos revendo esses critérios, os quatro: professor articulador, pedagógico, intercambista e político. Hoje, tem que ser feito com mais cuidado, porque tem outras pessoas fazendo isso também. No entanto, foi com muita luta que conseguimos todas as nossas especificidades e, hoje, a SEE que obrigar o professor a ficar apenas no âmbito pedagógico, quer que ele vire um professor branco. A gente sabe que isso não é possível, porque pra gente é diferente. A escola veio pra respeitar a gente e não a gente respeitar a escola. Ela chegou por último. A escola-prédio, o mundo da escrita e da leitura. Pelo menos com o início da escolarização diferenciada, a gente aprendeu a fazer política porque se não tivesse aprendido, pensa só? O que acontece atualmente é que o professor deixou um pouco essa coisa do político, de reivindicar os direitos, porque eles acham que, como funcionário do Estado, pode cortar o salário. Então, fazem na medida do que pode ser feito. E com isso, ficam presos. Essa coisa de professor-liderança fracassou porque não estão defendendo muito mais a causa. Quando chega as coisas, as políticas, tudo pra escola, eles não querem mais ver se serve pra comunidade, só recebe. E se a comunidade reclama, eles acabam sendo uma barreira. É isso que estamos vivendo hoje (Entrevista concedida em 26 de novembro de 2014).

Marli faz uma análise da conjuntura, em que o exercício do professor enquanto liderança ficou comprometido no momento em que a SEE assumiu a administração da educação escolar indígena. Afinal, desde o início do processo de escolarização, o que foi construído e ensinado para essas populações residia na política interétnica. Não do ponto de vista de que os povos indígenas não faziam política, mas sim, uma política institucional, o ato de fazer política para reivindicar direitos. Nesse contexto, a escola é um veículo de compreensão do mundo dos brancos, um mundo que se impôs sem nenhuma diplomacia. Assim, a escola vem da necessidade diplomática de atuar nessa sociedade envolvente.

Nessa perspectiva, o docente atua essencialmente como mediador, um filtro para o mundo dos brancos. Marli endossa o que Davi disse antes, que o professor é um assessor. No entanto, o Estado articulou a educação a outras esferas, de tal maneira que acabou aparelhando o professor indígena. $\mathrm{Ou}$ 
seja, a partir dessa técnica de torná-los funcionários via contratos temporários, o Estado mantém os indígenas na insegurança, afinal, não existem concursos públicos diferenciados para o cargo de docente que garantam a permanência em sala de aula e, consequentemente, o exercício das funções de político e assessor fica vulnerável. Logo, não se pode exercer muito bem nenhuma das duas frentes de trabalho, em virtude da submissão a duas esferas sociais completamente diferentes, totalmente divergentes.

Nesse caso, características de liderança na comunidade ficam comprometidas, visto que, como funcionário do Estado, muitas vezes o professor não reivindica direitos coletivos por insegurança ou medo, como, por exemplo, da já mencionada possibilidade de perda de salário. Isso coloca em xeque, ao mesmo tempo, o seu eventual exercício de generosidade na aldeia, bem como a demonstração de capacidade oratória que se espera dele. Dessa forma, esse sujeito está imerso em um labirinto criado pelo sistema burocrático.

A OPIAC, enquanto órgão representativo, passa a ter um papel de guia. Embora também esteja aparelhado, carecendo das condições plenas de atuar como interventor e reivindicador de direitos, não deixa de buscar recriar, diante da sociedade envolvente, seu papel de representação indígena:

A OPIAC está pra defender a política de educação indígena. O papel da OPIAC é fazer com que o professor seja beneficiado com todos os programas que o governo oferece: concurso público, formação, acompanhamento pedagógico, material didático, material escolar. A nossa obrigação é orientar esses professores de acordo com a legislação (Marli, coordenadora da OPIAC. Entrevista concedida em 26 de novembro de 2014).

Assim, cabe ao professor lidar com duas concepções opostas de sua categoria e, principalmente, do papel da escola na sociedade. O que está em jogo aqui são entendimentos divergentes de educação e de perspectivas de futuro, diante da sociedade envolvente.

\section{Ato 3: Comissão Pró-Índio do Acre (CPI)}

A categoria de professor indígena, por um lado, segue um recorte do professor clássico, aquele que tem um grupo de estudantes, que coordena, ensina, que está totalmente associado a letramento, alfabetização. Porque ter uma população não alfabetizada dentro dessas sociedades era um sinal de desigualdade, quer dizer, aprender a ler e escrever era ter acesso à informação pra acompanhar uma porção de coisas de fora. Que é diferente daquela educação Huni Kuin, com muita observação, experimentando, seguindo os conselhos dos mais velhos, enfim. Um universo complexo dos modos de aprender dessas sociedades. O professor tinha também que aprender esses modos, junto com essa escola. Isso constitui o ser nessas sociedades, a escola também tem que estar junto com esses modos tradicionais. Desde o começo, você tinha que lidar com uma escola com essa interculturalidade, pra eles e pra nós (Helena, coordenadora da CPI. Entrevista concedida em 14 de janeiro de 2015).

A CPI, como pioneira no processo de escolarização indígena no Estado do Acre, sempre buscou atuar em conjunto com esses professores e formá-los para a compreensão do mundo não in- 
dígena, em uma perspectiva de associação de conhecimentos de ambos os lados, que visa a garantir a cidadania indígena, em um Estado marcadamente indiferente e violento ao modo de viver dessas populações. Assim,

[e]sse professor foi participando desses cursos de magistério indígena justamente pra dar conta dessa concepção de escola diferenciada. Se, num primeiro momento, era ensinar aprender a ler e escrever no primeiro curso da CPI, posteriormente era lidar com toda complexidade que emana e circunda o ambiente deles. E aí o que acontece é muito difícil. Trabalhar a formação, qualificar, desenvolver e aprimorar certas competências em alguns indivíduos que eram esses professores. Então, a equipe da CPI voltava pra Terra Indígena com esses professores pra fazer o acompanhamento pedagógico, pelo menos uma viagem por ano. Era necessário e ainda é batalhar pelas condições de trabalho para o exercício dessa atividade docente. Acompanhamento pedagógico, relação dele na comunidade, os modos próprios de ensinar e aprender. Os materiais didáticos em língua indígena. O professor então é o sujeito com quem se conversava e com quem a gente trocava, a qualificação para quem chegava. Professor tinha que fazer tudo isso sozinho na comunidade. Essa categoria então passa por isso. Esse sujeito que está tendo uma formação, específica, qualificada e regular que tem que dar conta desse universo todo, de educação, de cultura, de construção de conhecimento, manutenção de conhecimento. Concentrado nele por conta dessa formação (Helena, coordenadora da CPI. Entrevista concedida em 14 de janeiro de 2015).

O projeto de instrumentalização desse sujeito oriundo de uma comunidade indígena abrange, desse ponto de vista, uma aquisição de conhecimentos, símbolos que o tornam importante dentro da comunidade, pois, além de alfabetizar os parentes, sua atuação tem por característica mobilizar a comunidade em prol da manutenção da terra, dos saberes tradicionais, entre outros. O fato de ser uma liderança é intrínseco a esse processo.

A categoria faz a integração de uma docência com modos, práticas e jeitos de ser muito próprios. O cuidado todo é que não se eliminasse esse jeito de ser indígena. Primeira pergunta: o que você quer aprender? E pra quê? Não existem no Brasil ambientes escolares que te dão essa oportunidade. Precisava ter essas figuras, com disponibilidade pra essa formação. Por que eles são lideranças? Do ponto de vista da formação e da informação, acabam sendo lideranças. Indivíduos que têm formação anual e regular e contato com várias culturas indígenas e a nossa não indígena. Então, isso é de uma riqueza para o ser humano. Eles se destacam por isso (Helena, coordenadora da CPI. Entrevista concedida em 14 de janeiro de 2015).

\section{Ato 4: Conselho Indigenista Missionário (CIMI)}

O ponto de partida é a compreensão de como os diversos atores e a própria comunidade indígena notam a educação escolar indígena. Acho que é um problema conceitual fundamental. Porque a concepção enquanto comunidade é uma coisa, sobre essa educação escolar, o que é o professor. E cursos, os espaços que o professor faz, são uma outra coisa. E o que a SEE discute, debate e, enfim, tenta implementar, é ainda uma outra coisa. Entendeu? Então, as relações em torno, não só do professor, mas em torno do conjunto dessas concepções, do que seria ou de como seria a educação escolar indígena, vêm com uma aura. É importante pra gente observar a questão da re- 
lação de poder da educação escolar, de um modo geral, e, evidentemente da indígena, de modo muito especial. Quando a própria constituição garante uma educação diferenciada, em que esse diferenciado pressupõe autonomia, a ideia, essa é a nossa leitura aqui do CIMI, o que está por trás é uma escola autônoma e não uma escola adequada. Porque autonomia é diferente de adequação. Ao se adequar, você nega a própria autonomia. Então, a simples existência administrativa da SEE é uma prova concreta de que não há essa autonomia das escolas indígenas. O que significa dizer que o diferenciado não existe, deixa de existir na medida em que não há autonomia. Não estamos falando de uma questão estrutural, estamos falando de uma questão pedagógica. O que estamos dizendo é: se a forma de transmitir conhecimentos e a forma de absorver esses conhecimentos não for autônoma do povo, então a educação escolar indígena é uma farsa (Pedro, indigenista do CIMI/AC. Entrevista concedida em 21 de novembro de 2014).

Pedro pontua em seu depoimento um conflito epistemológico sobre a educação diferenciada quando esta passa a ser orientada e coordenada pela SEE. Enfatiza a construção dessa política educacional como uma manobra de controle, principalmente nos estados com uma parcela significativa de populações indígenas. Contra essa situação, defende a autonomia dos povos indígenas em gestar, gerir e conduzir os próprios processos de escolarização.

Você tem muito limitado o lugar da escola e do professor. Isso é também entre os Huni Kuin, sabe? Então a participação na vida comunitária termina quando o indivíduo vira professor. Por exemplo, às vezes, quando o indivíduo está no ritual não é professor, é Huni Kuin. Mas tem esse papel de professor-liderança, essa figura pra sustentar. Essa é uma exigência moral, isso não está escrito em um papel de conduta. A SEE coloca essa exigência na cabeça do professor, é um grande mal. Coloca e funde lá dentro, entendeu? Isso aí está na cabeça dos Huni Kuin, na cabeça de todo mundo. Não por eles. Mas pelo modelo da nova economia, o nome disso é tutela. Tutela normal, por conta da Funai [Fundação Nacional do Índio], mas existem as tutelas específicas por conta de ONGs e secretarias. Então, a SEE exerce tutela sobre os professores. E essa tutela impede a autonomia. Impede os professores de serem eles mesmos. Eles deixam de ser Huni Kuin pra serem professores. Quando deixa de ser professor, volta a ser Huni Kuin. É uma coisa louca, porque não é assim na vida real deles. Não é assim. Pajé é pajé 24 horas por dia. Não existe isso. Então, esse modelo de separação começa exatamente com a escola nesse processo, quando faz isso. Você passa a ter papéis e isso é muito complicado. Porque a ideia de liderar, por exemplo, passa a ser falha. O professor enquanto professor, ele não pode ser líder. Está entendendo como é? Porque, efetivamente, o processo do exercício do professor não é dele próprio, é da SEE que tutela. Então, concretamente, quando um professor se posiciona como liderança, efetivamente, está liderando em nome de algo ou alguém. O poder de liderança dele não foi dado pelo povo. Mas pela SEE. E é a SEE que paga o seu salário. Isso é complexo. A gente não tem ideia. Mas isso atinge brutalmente a estrutura epistemológica do professor. Existe uma contradição interna, um sujeito que é do mundo, que circula pelo seu próprio mundo e o mundo do branco. E, de repente, está limitado a determinadas normas, diretrizes. Então, nós precisamos discutir isso. O resto é futilidade (Pedro, indigenista do CIMI/AC. Entrevista concedida em 21 de novembro de 2014).

A perspectiva que o CIMI adota do professor-liderança, bem como da própria escola, é redutível, no sentido de que tal papel surge imposto pelas instituições. Essa visão contradiz o próprio modo 
indígena de operar com o mundo dos nawá, como exposto antes. Os processos pelos quais a SEE e as ONGs tentam encaixotar a figura desse sujeito não se dão, necessariamente, como nas comunidades. São percepções muito divergentes a respeito desse ator em todas as esferas em que transita.

De fato, nem todo docente é visto por sua comunidade obrigatoriamente como liderança, mas ao sair da sua aldeia, opera como um embaixador, um porta-voz da sua cultura. É preciso comunicar no mundo do branco a sua origem, marcar uma posição enquanto representante e articulador do seu povo. Comunicar a alteridade para estabelecer uma relação e uma política interétnica. Reduzir essa atuação a simples controle da SEE no âmbito da aldeia é ignorar as especificidades, a lógica operacional da organização social à qual o professor corresponde.

Assim, cabe ressaltar que os olhares para esse sujeito, enquanto docente e liderança, são essencialmente baseados em visões etnocêntricas de relações de poder e da função de professor. Mediante essa perspectiva, o desenvolvimento do processo de educação escolar indígena fica comprometido, visto que os órgãos institucionais que a regulam e operacionalizam não compreendem e trabalham em conjunto com as comunidades, em suas respectivas particularidades. No entanto, cabe aos órgãos indigenistas construírem reflexões sobre essa escola indígena ainda em construção. No tópico a seguir, para fins de encerramento, discute-se como o corpo dessa escola coexiste mediante tantas perspectivas.

\section{Considerações finais}

Como visto ao longo do artigo, o professor-liderança é a personificação da escola na comunidade Huni Kuin. Figura enquanto representação da ponte entre os conhecimentos dos Huni Kuin e dos nawá. Isso posto como ponto de partida, vale ressaltar a importância dele como detentor, comunicador e, principalmente, tradutor desses saberes. Essa visão concebe a escola enquanto parte criada e constituída. É, por excelência, um espaço de elaboração de saberes, de maneiras variadas de viver, de agregar, dividir e somar.

A escola indígena, junto do professor-liderança, se elabora, ao mesmo tempo, diante da perspectiva das instituições da sociedade nawá, como também daquela da sociedade Huni Kuin, abraçando como um de seus fundamentos essenciais a incorporação de um projeto de interculturalidade. No entanto, do ponto de vista lógico, essa baliza intercultural está mais afinada com o discurso proferido pelos professores Huni Kuin e com a comunidade do Breu de uma maneira geral, que àquele dos órgãos institucionais com os quais mantêm uma relação direta.

Supõe-se dessa lógica uma troca de conhecimentos de maneira horizontal ou, minimamente, um desejo de simetria, da perspectiva dos Huni Kuin (a que aqui nos interessa) e que, por fim, algo está sendo dado, assim como, por ora, igualmente recebido. Porém, de acordo com as Secretarias de Educação, tanto municipal quanto estadual, há uma perspectiva de "troca" vertical. Mas como se dá essa suposta troca, a fim de estruturar, de fato, uma escola que constrói a educação Huni Kuin?

Entre os Huni Kuin, conforme salienta Lagrou (1998:39), as posições das relações são sempre permutáveis. Ou seja, "esta relação não denota uma reversibilidade de posições em que sujeito significa agência e objeto passividade, mas uma intersubjetividade em que ambas as posições apresentam a qua- 
lidade da agência e da subjetividade". A escola, enquanto estrutura ativa, é também passível de "regular" essas relações, como explicita McCallum (2005:229):

[...] por meio do engajamento com o mundo fenomenal - ou seja, com objetos e seres que, para os Huni Kuin, são concomitantemente materiais e imateriais, visíveis e invisíveis; a forma e a aparência dependem da condição corporal (consciente, inconsciente) do observador. As relações de proximidade nunca são dadas a priori, pois precisam ser construídas materialmente e reafirmadas sempre.

A percepção fina da questão consiste em compreender que, enquanto as instituições marcam sempre o fator diferencial da educação escolar indígena como primordial e vertical, os indígenas buscam continuamente marcar, apesar de contradições internas sobre concepções do que é e do que deve ser a escola Huni Kuin, o fator intercultural diante de uma perspectiva de troca horizontal, de desejo pela simetria.

Nessa visão cosmológica dos Huni Kuin, a escola, enquanto espaço de construção de conhecimentos diferenciados e interculturais na e para a comunidade, atua pontualmente na objetificação da troca, do ponto de vista da diferença e da identidade, pois, "[...] para ser capaz de lidar com a alteridade deve-se aprender a tornar-se outro ou imitar o ser outro no sentido de captar seu ponto de vista no mundo e, assim, ganhar poder sobre a situação interativa” (Lagrou, 1998:39). Contudo, a perspectiva adotada pela SEE e SME não condiz com esse desejo, o ideal de simetria, mas sempre se dirige à aspiração de "encaixotar" e enrijecer os conhecimentos pertinentes à escola, principalmente aos sujeitos que dela participam. O erro persiste em configurar a escola indígena sempre nos moldes da escola do nawá.

Sob essa luz, sempre será desafiador conduzir um processo de pedagogia libertária, autônoma e eficaz. Pois, o discurso não se alinha à prática e a ausência de assessoria pedagógica na construção de concepções de educação diferenciante arruína as possibilidades diversas das escolas indígenas. Conforme expõe Freire (2010:44), a

[...] educação que, desvestida da roupagem alienada e alienante, seja uma força de mudança e libertação. A opção, por isso teria de ser também, entre uma 'educação' para a 'domesticação', para a alienação, e uma educação para a liberdade. 'Educação' para o homem-objeto ou educação para o homem-sujeito.

Assim, o professor-liderança é um agente importante na transmutação e comunicação de conhecimentos, seja para a comunidade indígena, seja para os agentes públicos que se inter-relacionam com as suas compreensões no que tange à escola. Esse docente corporifica, de fato, a escola Huni Kuin.

\footnotetext{
Maria Zenaide Gomes de Castro é Mestre em Educação pela Universidade Estadual de Campinas (UNICAMP) e Professora de Educação Básica na Secretaria de Estado do Distrito Federal (SEEDF). Foi bolsista da Coordenação de Aperfeiçoamento de Pessoal de Nivel Superior (Capes) entre 2013 e 2015.
} 


\section{REFERÊNCIAS}

Bergamaschi, M. A., \& Medeiros, J. S. (2010). História, memória e tradição na educação escolar indígena: o caso de uma escola Kaingang. Revista Brasileira de História, 30(60), 55-75. https://doi. org/10.1590/S0102-01882010000200004

Brasil. Ministério da Educação. (2014). Diretrizes Curriculares Nacionais para a Formação de Professores Indigenas. Disponivel em: http://portal.mec.gov.br/index.php?option=com_content\&view=article\&id=21013\%3Adiretrizes-para-a-formacao-de-professores-sao-homologadas\&catid=202\&Ite$\operatorname{mid}=86$

Brasil. Congresso Nacional. (2001). Lei n. 10.172, de 9 de janeiro. Aprova o Plano Nacional de Educação e dá outras providências. Disponível em: http://www.planalto.gov.br/ccivil_03/leis/leis_2001/ 110172.htm

Brasil. Ministério da Educação. (1998) Referencial Curricular Nacional para as Escolas Indigenas. Brasília: MEC/SEF.

Brasil. Conselho Nacional de Educação. (1999). Parecer CNE/CEB n. 14. Diretrizes Curriculares Nacionais da Educação Escolar Indígena. Brasília: MEC.

Brasil. Conselho Nacional de Educação. (1999). Resolução CNE/CEB n. 03. Diretrizes Nacionais para ofuncionamento das escolas indigenas. Brasília: MEC.

Brasil. Congresso Nacional (1996). Lein. 9.394, de 20 de dezembro. Estabelece as Diretrizes e Bases da Educação nacional. Disponível em: http://www.planalto.gov.br/ccivil_03/leis/19394.htm

Carneiro da Cunha, M. (1999). Xamanismo e Tradução. In A. Novaes (org.). A Outra Margem do Ocidente (pp. 223-236). São Paulo: Companhia das Letras.

Carneiro da Cunha, M. (2009). "Cultura” e cultura: conhecimentos tradicionais e direitos intelectuais. In: Cultura com aspas e outros ensaios (pp. 311-373). São Paulo: Cosac Naify.

Clastres, P. (2003). Troca e poder: filosofia da chefia indígena. In: A Sociedade contra o Estado - pesquisas de antropologia politica (pp. 45-63). São Paulo: Cosac \& Naify.

Clastres, P. (2004). Arqueologia da Violência. São Paulo: Cosac \& Naify.

Cohn, C. (2005). Educação escolar indígena: para uma discussão de cultura, criança e cidadania ativa. Perspectiva, 23(02), 485-515.

Cohn, C. (2014). A Cultura nas Escolas Indígenas. In P. de N. Cesarino, \& M. C. da Cunha. Políticas culturais e povos indiggenas (pp. 313-338). 1ª ed. São Paulo: Cultura Acadêmica. 
Ferreira, P. R. N. (2010). Na remenda do céu com a terra: escolas diferenciadas não são Huni Kuĩ. (Dissertação de Mestrado). Universidade Federal do Paraná, Curitiba.

Francheto, B. (2006). Notas em torno de discursos e práticas na educação escolar indígena. In L. D. B. Grupioni (org). Formação de professores indígenas: repensando trajetórias (pp. 191-198). Brasília: Ministério da Educação, Secretaria de Educação Continuada, Alfabetização e Diversidade.

Francheto, B. (2010). Micol Brazzabeni, "La Scuola di Carta: una ricerca di antropologia dela formazione tragli insegnanti tikmu’un del minas gerais”. Etnográfica, 14 (2), 407-411. https://doi. org/10.4000/etnografica.344

Freire, P. (1967). Educação como prática da liberdade. Rio de Janeiro: Paz e Terra.

Guerreiro Júnior, A. R. (2011) Aliança, chefia e regionalismo no Alto Xingu. Journal de la société des américanistes, 97(2), 99-133. https://doi.org/10.4000/jsa.11902

Grupioni, L. D. B. (2013). Quando a Antropologia se defronta com a Educação: formação de professores índios no Brasil. Pro-Posições, 24(2), 69-80. https://doi.org/10.1590/S010373072013000200006

Grupioni, L. D. B. (2008). Olhar Longe, porque o Futuro é Longe: cultura, escola e professores indigenas no Brasil. (Tese de Doutorado). Universidade de São Paulo, São Paulo.

Gusmão, N. M. M. (1997). Antropologia e Educação: Origens de um diálogo. Cad. CEDES, 18(43), 8-25 . https://doi.org/10.1590/S0101-32621997000200002

Huni Kuin, J. P. M. et al. (2002). Índio do Acre: História e Organização. 2 ed. Rio Branco: Comissão Pró-Índio do Acre.

Lagrou, E. M. (1991). Uma Etnografia da Cultura Huni Kuin: Entre a Cobra e o Inca. (Dissertação de Mestrado). Universidade Federal de Santa Catarina, Florianópolis.

Lagrou, E. M. (1998). Caminhos, Duplos e Corpos. (Tese de Doutorado). Universidade de São Paulo, São Paulo.

McCallum, C. (1998) Alteridade e Sociabilidade Kaxinauá: Perspectivas de uma antropologia da vida diária. Revista Brasileira de Ciências Sociais, 13(38), 127-136. https://doi.org/10.1590/S010269091998000300008

McCallum, C. (2013). Intimidade com estranhos: Uma perspectiva Huni Kuin sobre confiança e a construção de pessoas na Amazônia. Mana, 19(1), 123-155. https://doi.org/10.1590/S010493132013000100005 
McCallum, C. (2015). Espaço, pessoa e socialidade ameríndia: sobre os modos Huni Kuin de relacionalidade. Revista de Antropologia, 58(1), 224-256. https://doi.org/10.11606/2179-0892. ra.2015.102107

Sampaio, J. A. L. (2006). O resgate cultural como valor: reflexões antropológicas sobre a formação de professores indígenas. In L. D. B. Grupioni (org). Formação de professores indígenas: repensando trajetórias (pp. 165-174). Brasília: Ministério da Educação, Secretaria de Educação Continuada, Alfabetização e Diversidade.

Seeger, A., DaMatta, R., \& Viveiros de Castro, E. (1979). A construção da pessoa nas sociedades indígenas brasileiras. Boletim do Museu Nacional, 32, 2-19.

Tassinari, A. M. I. (2001). Escola Indígena: novos horizontes teóricos, novas fronteiras de educação. In: A. L. da Silva, \& M. K. L. Ferreira (orgs). Antropologia, História e Educação: a questão indígena e a escola (pp. 44-70). São Paulo: Global.

Weber, I. (2004). Escola Kaxi: História, Cultura e aprendizado escolar entre os Kaxinawá do Rio Humaitá (Acre). (Dissertação de Mestrado). Museu Nacional, Universidade Federal do Rio de Janeiro, Rio de Janeiro.

Weber, I. (2006). Um Copo de Cultura: os Huni Kuin do Rio Humaitá e a escola. Rio Branco: EDUFAC. 


\section{O PROFESSOR-LIDERANÇA HUNI KUIN DO BREU E OS SEUS CONTEXTOS DE ATUAÇÃO: UMA ETNOGRAFiA DAS RELAÇÕES}

Resumo: A categoria professor-liderança é enunciada constantemente entre os Huni Kuin, povo indígena que habita uma extensa faixa territorial entre o Brasil e o Peru. Emergem, assim, questionamentos a respeito desse sujeito como mediador essencial entre a escola, aldeia e as instituições estatais representantes da educação. O objetivo deste artigo é analisar esses contextos em que os professores indígenas Huni Kuin estão inseridos e, principalmente, as relações que constituem nesse universo, com Secretarias de Educação (Municipal e Estadual), Organizações Não Governamentais e suas respectivas comunidades.

Palavras-chave: Huni Kuin; Educação escolar indígena; professor; liderança; relações interétnicas.

THE HUNI KUIN TEACHER-LEADER FROM BREU VILLAGE AND YOUR ACTING CONTEXTS: AN ETHNOGRAPHY OF RELATIONSHIPS

Abstract: The teacher-leader category is constantly enunciated among the Huni Kuin, an indigenous people who inhabit an extensive territorial strip between Brazil and Peru. Thus, questions emerge about this personage as an essential mediator between the school, village, and state institutions representing education. The objective of this article is to analyze these contexts in which the Huni Kuin indigenous teachers are inserted and, mainly, the relationships that constitute in this universe, with Education Secretariats (Municipal and State), Non-Governmental Organizations, and their respective communities.

Keywords: Huni Kuin; Indigenous School Education; Teacher; Leader; Interethnic Relations.

RECEBIDO: $30 / 04 / 2020$

ACEITO: $11 / 01 / 2021$ 